\title{
DEVELOPMENT OF HYDRAULIC PULL- METER TO COMPATIBLE WTH MONOTERING DATA INSTRUMENT
}

Bahnasy,A.M.F.;A.A El-Gwady;A.A.I. Mohamed and M. M. Metwalli Agric. Eng. Research Institute, Giza- Egypt.

\begin{abstract}
The hydraulic pull-meter and strain pull-meter are normally used to test tractors and agricultural machines. Each one has advantage and disadvantage. Data obtained from the hydraulic pull-meter is steady and is recorded manually from its dial. So, at the high speeds, it is hard to record data accurately as the responsible man for the measurements should run beside the tractor at its speeds. Also, few readings usually record especially at high speeds. On the other hand, readings obtained from strain pull-meter are too many at any tractor's speed as they are recorded and stored automatically. Reading obtained from strain pull-meter is not steady.

So, in the present study, the hydraulic pull-meter was developed to have the advantages of both pull-meters. The development was done by engaging a designed vessel electronic device to its outlet fluid line to convert the manual dial reading to an electronic reading. The design calculations indicated that the maximum draft can be applied to the developed vessel electronic device is up about to $68.6 \mathrm{kN}$.

Laboratory and field tests were carried out using the developed pull-meter and pre-calibrated strain pull-meter. In addition to a pre-calibrated hydraulic pull-meter. The static analysis of the laboratory results showed that the correlation coefficient $\left(R^{2}\right)$ of the developed hydraulic pull-meter was higher than that of the strain pull-meter compared with the pre-calibrated hydraulic pull-meter.

Field test results, on clay soil, showed that the error was higher than that at the laboratory calibration. They were $8 \%$ and $33 \%$ for the developed hydraulic pull-meter and strain pull-meter compared with the pre-calibrated hydraulic pull-meter.
\end{abstract}

\section{INTRODUCTION}

Farming machinery testing and evaluating center equipped with precise tools for measuring and evaluating performance parameters. So that to accurate data, they can provide a realistic analysis, use of this type of systems to outfit tractors and measure the technical parameters are growing. Study and research works related to tractors performance assessment need accurate strain force measurement, for accurate measurement of tractor performance researchers have used different methods.

Jhon Wiley (1994) Described methods of strain gage instrumentation for engineering usage, strain gage sensor constructing, and methods of operating data acquisition system.

El-Gwadi (2005) developed a strain gage transducer to fit most rotary implements, The importance of this slip ring part is the mean part which transmit pulses developed through both the torque sensor, and rpm sensor located on the rotating coupling to the stationary data acquisition system located on the tractor cabin.

Minhang et al., (2003) described a novel calibration scheme for fast accurate calibration of high sensitivity pressure transducers based on theoretical analysis, the accuracy of the calibration for non-linearity; 
hysteresis and repeatability can be much higher than $1 \times 10.4$, for pressure transducers with an operation range of $1 \mathrm{kPa}$ or below. Chen et al., (2007) designed a 2D double extended octagonal ring (DEOR) drawbar dynamometer with a draft capacity of $180 \mathrm{kN}$ was developed. The two extended octagonal rings were oriented vertically on either side of the tractor drawbar which provided a better match of strain to expected drawbar draft Chattopadhyay et al., (2012) designed a C-shaped Bourdon tube acts as a primary sensor and is connected with pneumatic pressure set up. With the change of the air pressure in the Bourdon tube, the tip displacement and AC output voltage changes with the displacement of the ferromagnetic core; this is directly proportional to the applied pressure. ASME B31 (2001), explained the design formula of the allowable internal pressure for any copper tube hollow tube formula.

Mohamed et al., (2001) designed a data acquisition system for measuring the tractor performance parameters. This system measures static and dynamic rear axial force, power and speed.

The specific objectives of the study is developed a locally and an inexpensive vessel electronic device, based on data acquisition system using strain gauge method, to covert the manual dial reading of a hydraulic pullmeter to an electronic reading.

\section{MATERIALS AND METHODS}

The construction of the developed vessel electronic device was achieved at Testing and Research Station for Tractor and Farm Machinery, Alexandria governorate, AENRI, Egypt. The developed vessel was made of copper equipped with a strain gauge forming Wheatstone bridge attached around the wall vessel on its outside as shown in Figure. (1)

A standard hollow copper cylinder vessel which available at the market dimensioned of outer and inside diameters of $34 \mathrm{~mm}$, and $30.4 \mathrm{~mm}$, is equipped from one side with a screw cap for oil drain after work, and from the other side inlet for pressed oil income from the engaged hydraulic pull-meter. This inlet side is attached to a standard T pipe which connects the vessel to the hydraulic pull-meter output. This T connector has three inlets, one in the middle attached to the vessel inlet, the other two ends one attached to the hydraulic pull-meter inlet, and the other attached to the hydraulic pull-meter dial. Thus both manual reading from the dial and the electronic data recording from the developed vessel can be recorded at the same time for vessel calibration. Method of wiring and installation of the Wheatstone strain gauge bridge, where R1, R3, mounted horizontally and R2, R4 mounted vertically for strain gauge heat compensation. The developed device was constructed and engaged to the outlet of the hydraulic pull-meter, in order to convert the hydraulic pressure induced in this hydraulic pull-meter to electric pulses. As the hydraulic pull-meter pressed oil passes throw the developed vessel, it effects on the vessel inside wall. The strain gage located outside this wall sense this pressure and converts it into electronic pulses. These pulses could be easily collected and stored using both a daytronic device, for data collecting and a computer for data recording and storing. 


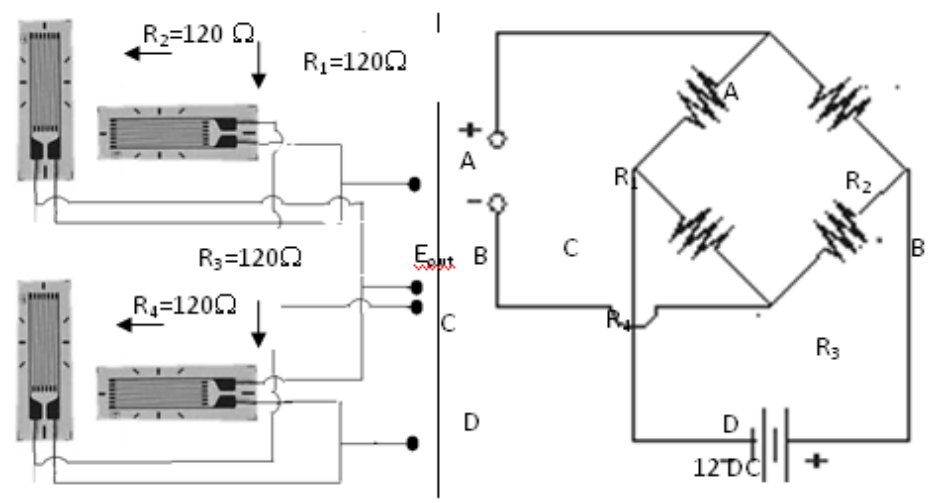

Fig (1): Wiring diagram of the Wheatstone strain gauge bridge on the vessel electronic device.

This modified pull-meter interfaced to a daytronic data PAC model 10k4 for strain gauge pulses collection and curing to engineering units in Newton, the Daytronic is then interfaced with laptop computer for data recording and storage during both calibration and actual agricultural field test. The hydraulic pull-meter connected to the vessel is $68.6 \mathrm{kN}$ tension capacity. It normally used for traditional tractor and agricultural implement draft measurement. A pre-calibrated strain gauge pull meter of $100 \mathrm{kN}$ calibrated in the faculty of engineering, Alexandria $U$. was used to calibrate the developed hydraulic pull-meter. Hydraulic loading cell capacity of 150 k.N was used to add load during calibration. Figure. (2) shows developed hydraulic pull-meter, while Fig. (3) shows a schematic of the developed vessel with its dimension.

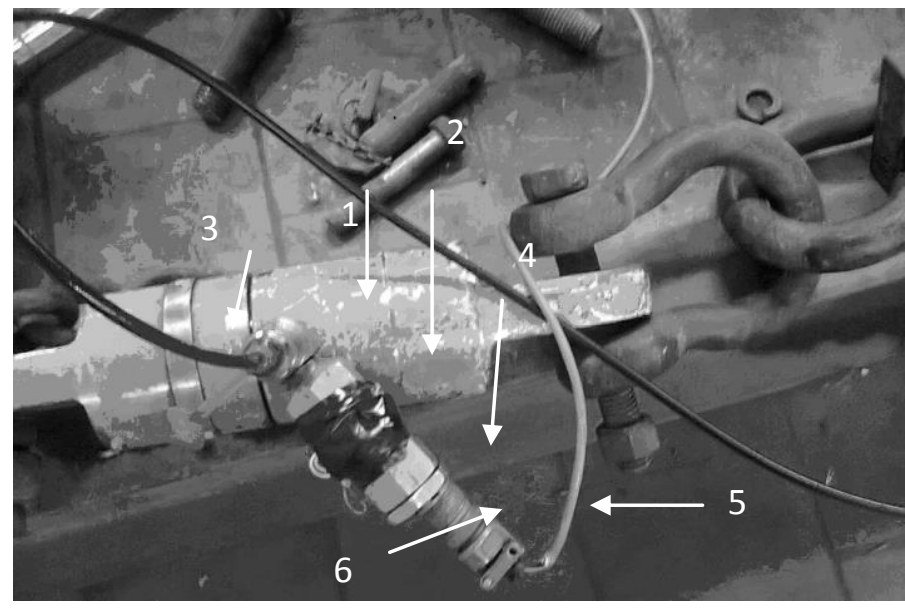

Fig. (2) A photo of the developed hydraulic pull-meter

1-Traditional hydraulic dynamometer

2- Vessel connector to dynamometer oil outlet

3- Oil inlet to dynamometer dial
4- vessel cylinder

5- Strain gage vessel wire socket 


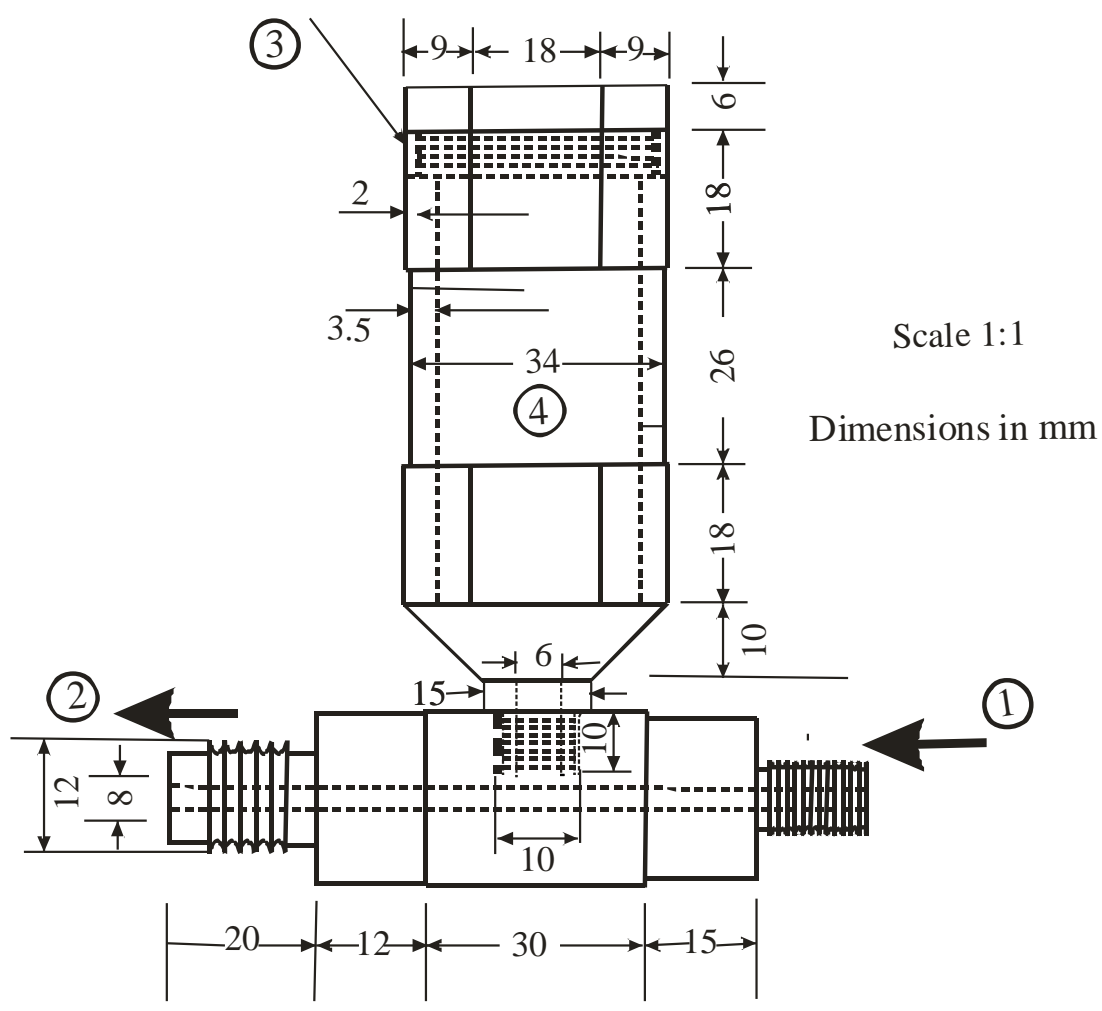

1 fluid entrance from hydraulic dynamometer 2 output fluid to Dail 3 vessel cup 4 vessel cylinder

Fig.(3) shows a schematic of the developed vessel

Determination of maximum draft on the developed vessel device transducer:

As for all materials, the allowable internal pressure for any copper hollow tube in service is based on the formula used in the American Society of Mechanical Engineers Code for Pressure Piping (ASME B31):

$$
\mathrm{P}=\frac{2 \mathrm{~S}\left(\mathrm{t}_{\min }-\mathrm{C}\right)}{\mathrm{D}_{\max }-0.8\left(\mathrm{t}_{\min }-\mathrm{C}\right)}
$$

Where:

$P=$ allowable pressure, $\mathrm{N} / \mathrm{mm}^{2}$

$\mathbf{S}=$ maximum allowable stress in tension, $\mathrm{N} / \mathrm{mm}^{2}$

$\mathbf{t}_{\min }=$ wall thickness (min.), $\mathrm{mm}$.

$\mathbf{D}_{\max }=$ outside diameter (max.), $\mathrm{mm}$.

$\mathbf{C}=$ a constant, equal Zero 
According to ASME, B31, the factor $\mathrm{C}$ to be zero. Then the formula becomes:

$$
\mathrm{P}=\frac{2 \mathrm{St}}{\mathrm{D}_{\min }-0.8 t_{\text {min }}}
$$

The value of $\mathbf{S}$ in the formula is the maximum allowable stress (ASME B31) equals $137.89 \mathrm{~N} / \mathrm{mm}^{2}$, in this study a hollow copper tube of $D_{\max }$, were chosen to equal, $26.8 \mathrm{mms}$ for the developed vessel, according the hydraulic pull meter design the maximum pressure $(P)$ almost $40.1 \mathrm{~N} / \mathrm{mm}^{2}$, for this cross section of $1712 \mathrm{~mm}^{2}$, means that a tractor of approximately maximum draft of $68.6 \mathrm{kN}$ on drawbar could be tested using this developed vessel transducer. The inner thickness and outer diameter of the vessel are subject to be increased to sustain tractors of higher drawbar draft as desired. So, maximum draft would be applied to this developed vessel transducer would be after calculation as $68.6 \mathrm{kN}$. From the above equation the vessel wall thickness should be equal to $3.5 \mathrm{~mm}$.

\section{Data acquisition system:}

A daytronic data PAC model 10k4, include two channels capable to convert the voltage signal of strain gage circuit output to the desired SI units in Newton, channel one reads loads applied to the pre-calibrated strain pullmeter, while channel two reads the same loads which applied to the developed hydraulic pull-meter, refer to load applied on each load sensor the developed hydraulic pull-meter was calibrated. As data PAC unit conditioned the output signal and record it into proper engineering SI units; a computer was interfaced to daytronic data PAC to illustrate and store these incoming data for later analysis.

\section{Calibration of the developed hydraulic pull-meter:}

As shown in Figure (4), a sit up of a steel bar, chain, pre-calibrated strain pull-meter and a hydraulic loading cell were used to calibrate the developed pull-meter for draft measurement. The hydraulic loading cell was used to add load of $12 \mathrm{kN}$, to the tested pull-meters as a reference unit. The tested devices were coupled with data acquisition system to measure the specific loads. A total load of $12 \mathrm{kN}$ was applied, that was increased from zero to $12 \mathrm{kN}$ with increments of $500 \mathrm{~N}$; loads were applied gradually, then the applied load was decreased incrementally of $500 \mathrm{~N}$ until zero loads is attained to both the pre-calibrated strain pull-meter and the developed hydraulic pull-meter. Reference load applied to the pre-calibrated pull-meter was drawn versus the load measured for the developed pull-meter. Loads were collected using Data Acquisition system and were recorded and stored using the interfaced computer. 


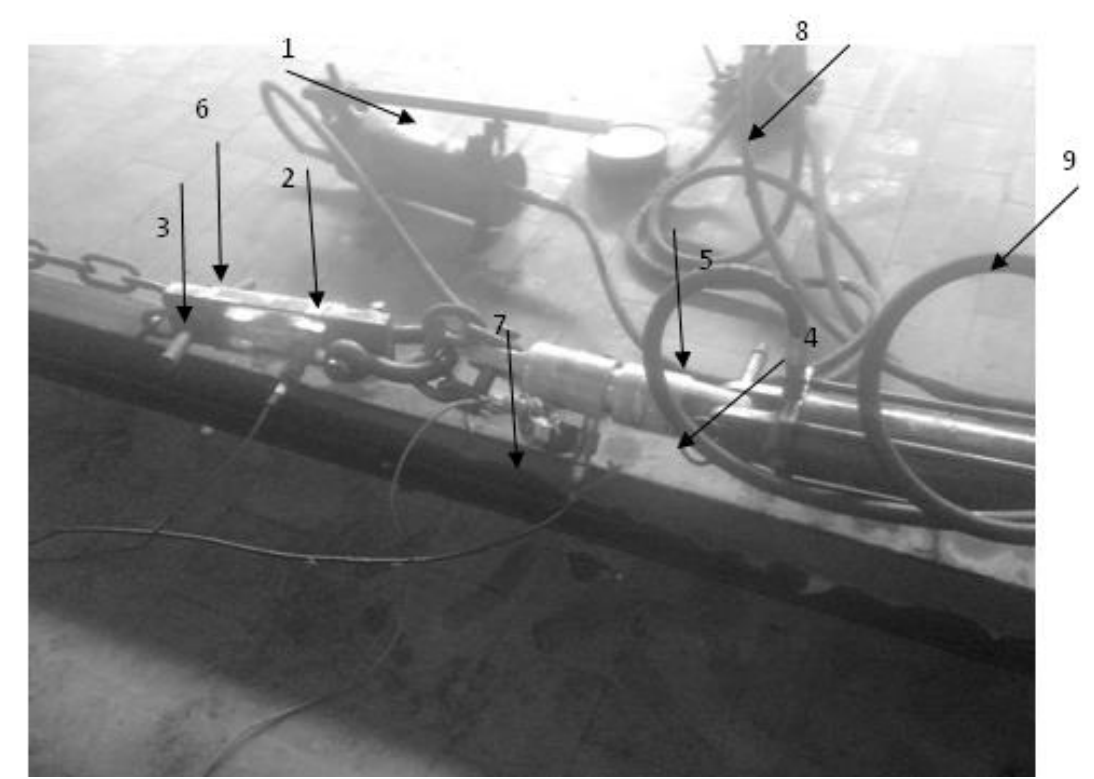

Fig. (4): Calibration set-up for the developed hydraulic pull-meter

\section{Hydraulic loading cell \\ 4 Developed vessel}

7 Vessel electric wire
2 Pre-calibrated strain gauge dynamometer 5 Traditional hydraulic dynamometer

8 The hydraulic dynamometer dial
3 Steel bar

6 Chain

9 Load cell hose

\section{Field test}

Field test was performed on clay soil by engaging the developed pullmeter in serial with the pre-calibrated pull-meter between two tractors using a chain. The front towing tractor towed the rear loading tractor at different forward speeds. The developed pull-meter and the pre-calibrated pull-meter were connected to two daytronic channels. The daytronic was interfaced to a computer for draft recording data. The daytronic and the interfaced computer were installed in the front tractor cabin.

\section{RESULTS AND DISSECTION}

The developed electronic vessel device was attached to a hydraulic pull-meter to be used as an electronic method to determine tractor draft instead of traditional manual dial recording.

\section{Calibration results}

The developed hydraulic pull-meter was calibrated and tested to be used as a precisely method in the field to determine the Agricultural implement and tractor draw power requirements. Data obtained from the static calibration between applied forces recorded by a pre-calibrated strain 
pull-meter and the developed hydraulic pull-meter was plotted as shown in Figure (5).

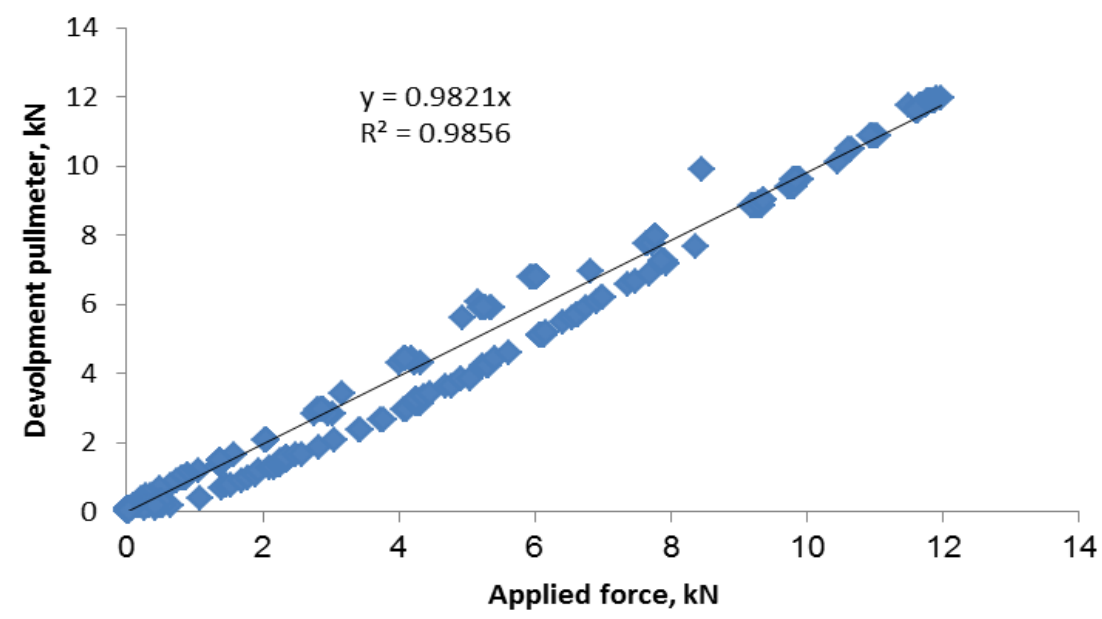

Fig. (5): Laboratory calibration for developed pull-meter

Data obtained from the laboratory calibration between the developed hydraulic pull-meter and the attached hydraulic pull-meter dial in bar was shown in Figure. (6).

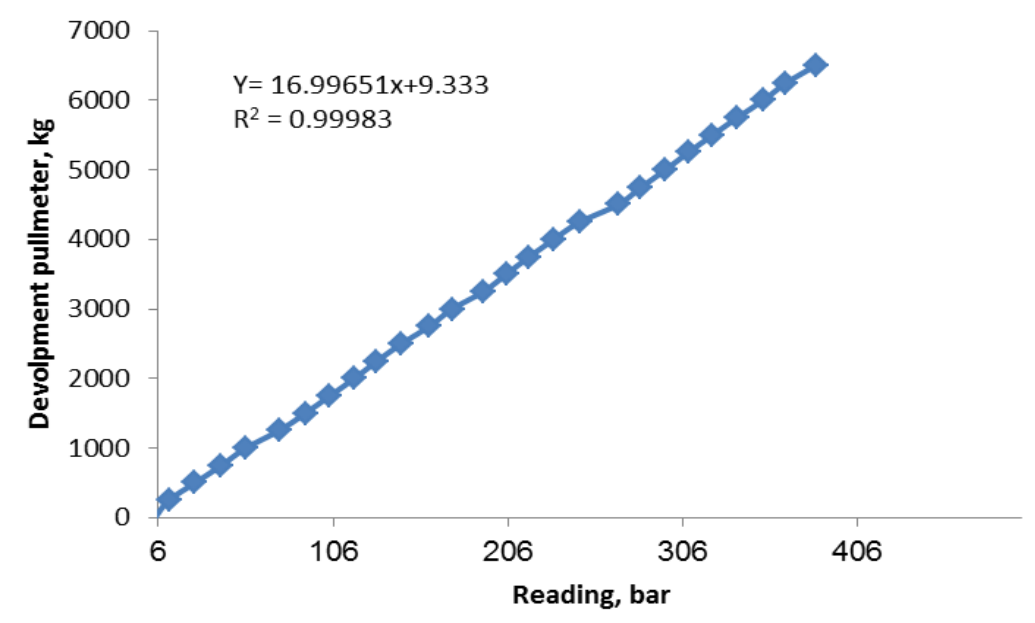

Fig. (6): The developed pull-meter and the hydraulic pull-meter dial in bar

The laboratory calibration of hydraulic, stain and developed pull-meters were illustrated as shown in Figure (7). The regression analysis between hydraulic, strain and developed pull-meters showed that the correlation 
coefficient $\left(R^{2}\right)$ of the developed pull-meter is higher than that of strain pullmeter and the slope of trend line is closer to hydraulic dynamometer. The equations bellow showed the behavior of both relationship between the developed pull-meter and strain pull-meter with the hydraulic pull-meter.

$$
\begin{array}{ll}
Y_{\text {vessel }}=0.912 x+70.78 & R^{2}=0.985 \\
Y_{\text {Strain }}=0.948 x-76.74 & R^{2}=0.963
\end{array}
$$

Where:

$\mathrm{Y}_{\text {vessel }}=$ New device reading, $\mathrm{N}$

$\mathrm{Y}_{\text {Strain }}=$ Strain gage pull meter reading, $\mathrm{N}$

$\mathrm{X}=$ hydraulic dynamometer reading, $\mathrm{N}$

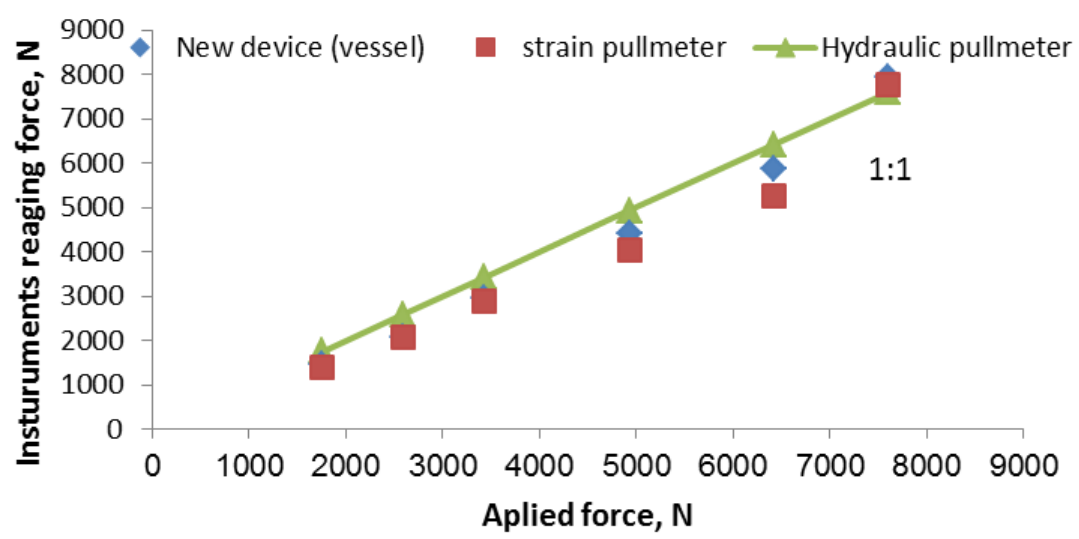

Fig. (7): Laboratory calibration for hydraulic, strain and developed pullmeter.

The complete randomization statistical analysis of field test is shown in Table (1). It's clearly that there is a difference between the two pull-meters. The Standard Deviation of the developed pull-meter readings of 35, whereas it is 64 for strain pull-meter these values means that the readings for strain pull-meter were more insatiable during the field test than the developed pullmeter. This observation is also clearly noticed with the value of coefficient of coloration between the two pull-meters which is equal to 0.74 . The error was higher than that at the laboratory calibration. They were $8 \%$ and $33 \%$ for the developed hydraulic pull- meter and strain pull- meter compared with precalibrated hydraulic pull-meter The mean reading of the develop pull-meter was $252 \mathrm{~kg}$ which is closed to the reference hydraulic pull-meter of $275 \mathrm{~kg}$. On the other hand, the mean of readings of strain pull-meter was $366 \mathrm{~kg}$. Difference between field and the laboratory results is because the new device was capable to absorbed field chook occurred by sudden pull by the hydraulic oil flow on its system. 
Table (1): Statistical analysis of strain and developed pull-meters.

\begin{tabular}{|l|c|c|}
\hline & Developed pull-meter & Strain pull-meter \\
\hline Mean & 252.3 & 366.2 \\
Standard Error & 6.4 & 11.7 \\
Median & 250.0 & 347.5 \\
Standard Deviation & 35.1 & 64.0 \\
Sample Variance & 1232.3 & 4094.9 \\
Skewness & 0.8 & 1.9 \\
Range & 160.0 & 282.0 \\
Minimum & 190.0 & 285.0 \\
Maximum & 350.0 & 567.0 \\
\hline
\end{tabular}

\section{CONCLUSION}

The developed vessel electronic device equipped with a strain gauge Wheatstone bridge, when engaged with any hydraulic pull-meter, could be interfaced with both daytronic data PAC for electronic data recording and a computer for data storage and data recording, this system could be used as an electronic sensor for precisely agricultural implement and tractor draft measurements. The developed pull-meter reading introduced a good result of tractor pull comparing to the other two devices (attached hydraulic and strain gage pull-meters). This satisfied results of the developed pull-meter are according to statically analysis specially at field operation.

\section{REFERENCES}

American Society of mechanical Engineers Code for Pressure Piping (ASME B31) (2001). B31. Code for pressure piping, developed by American Society of Mechanical Engineers-Process Piping, page9. INDEX 1.3 ASMA Code for Pressure Piping.

Chattopadhyay. S, J. Sarkar and S.C. Bera, (2012) A low cost design and development of a reluctance type pressure transducer

El-Gwadi, A. A. (2005). Developing a localey manufactured slip ring torque transducer for pto operating implements. Annual Conference of the Misr Society of Agr. Eng., 14-15 December 2005.

Jhon Wiley (1994). Text book of Instrumentation for engineering copy right. Printed in the United State of America. J Res Sci Teach., 36: 977-1019.

Minhang B., Yuancheng Sun, Y.Heng and W. Jinsuo. A fast and accurate calibration method for high sensitivity pressure transducers. Department of Micro Electronics, Fudan University, Shanghai 200433, PR China

Mohamed, A. A. I.; E. R.; El Ashry, Kh. A. A Khader,. and A. M. F .Bahnasy, (2001) Design an instrumentation system to determine the tractor performance. Misr j.Eng. 18(3): 527-536.

Chen, Y; N.B. McLaughlin and B.S. Tessier (2007). Double extended octagonal ring (DEOR) drawbar dynamometer, Department of Bio systems Engineering, University of Manitoba, Winnipeg, Man., Canada R3T 5V6, Soil \&Tillage Research., 93: 462-471. 
Bahnasy, A. M. et al.

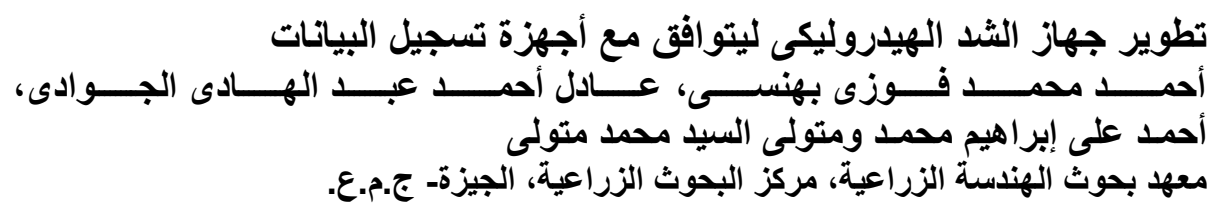

تم تطوير جهاز الثند الهيدروليكى التقليدى الخاص بأختبار قوة الثند للجرارات والآلات الزراعية

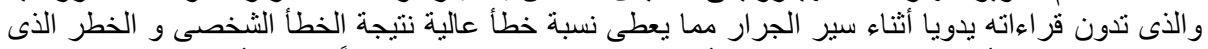

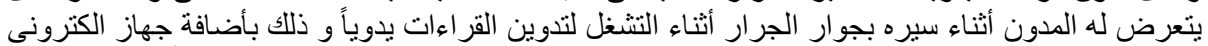

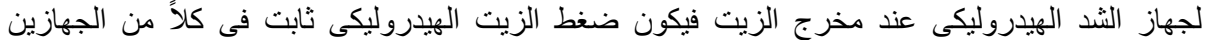

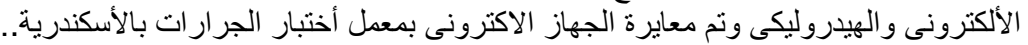

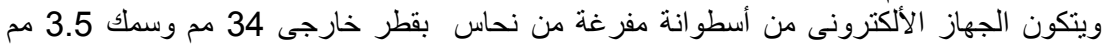

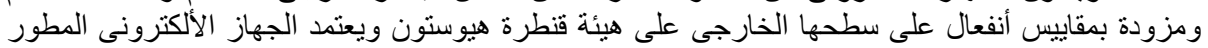

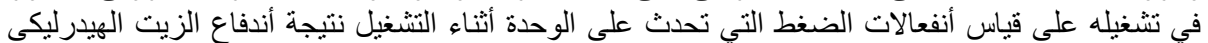

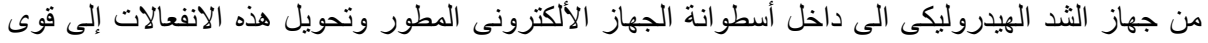

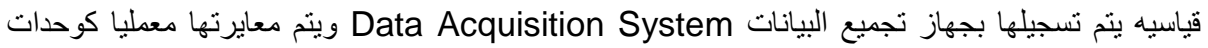
طاقة.

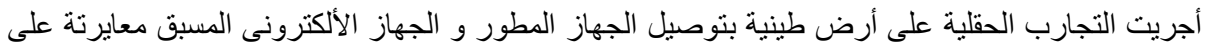

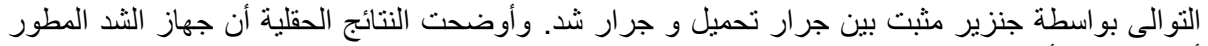

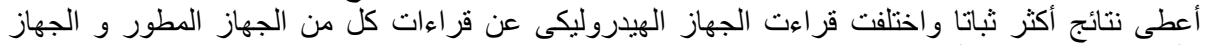

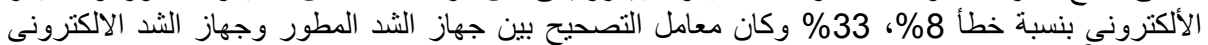

$\mathbf{R}^{2}=0.74$

توصى الدراسة بتصنيع الجهاز المطور محلياً لإمكانية دراسة قوى الثد للجرار بطريقة ألكترونية أمنه و

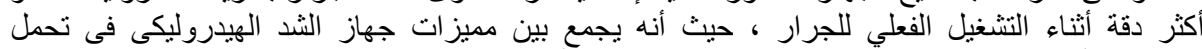

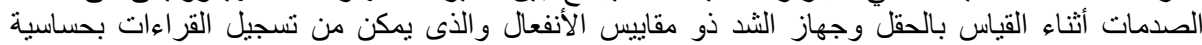
أعلى وبكمية تصل إلى قراءة كل ثانية. 